\title{
The Design and Application of Mechanical Automation Technology in Food Factory Network Management System Based on Fractional Algorithm
}

\author{
$\mathrm{Xu} \mathrm{Xi}{ }^{*}$
}

School of Mechanical and Electrical Engineering, Shenzhen Polytechnic, Shenzhen, China

\begin{abstract}
With development of mechanical and electronic technology, mechanical automation technology plays an important role in many areas. Because of high demand for food safety, mechanical automation technology in food factory is used widely. But there still is gap with advanced countries, mainly in automation software design. Through designing the automation monitoring system of food packaging production line, general process of automation control software design is introduced. And the results shows current machines are potential to work automatically and efficiently and produce goods with low lost and high quality.
\end{abstract}

Keywords: Automation control design, food packaging, mechanical automation, monitoring system.

\section{INTRODUCTION}

The food industry has become one of the most important basic industry in national economy of China and it is also called the eternal sunrise industry. With industry constantly upgrading and rapid economics development in our countrys, food industry become more and more large-scale and autornated. The research of the automated production line equipment management that is important to guarantee the safety and stability of product quality and reduce the enterprise production cost. It is the problem of enterprise urgently needs to solve problems effectively [1].

Mechanical automation technology began in 1920, and developed in next few decades. The appearance of computers provides promoting possibility for the mechanical automation technology [2]. In advanced countries, mechanical automation technology is used to aerospace, automobile, agriculture widely. China is also on the road explore machinery automation technology [3]. But there still an enormous gap in machine types, qualities, employment between china and the developing countries.

Since 2009, a lot of money is putted in mechanical automation transformation of food factory by food production enterprises [4]. With automation technology is pulled in, market competitiveness and technology level is promoted in food industry. Although there is an enormous improvement, the gap with advanced countries is still obvious. Machinery Automation work of food industry in China is major in single machine, with low technology and automation degree. Especially, new technology, new process, new material is developed slowly, not matching with development in food industry. And the gap will be widen, because of immature innovation system and mechanism [5].

Only mechanical automation can help food industry survive in challenges. Reducing costs, improving food quality, increasing earning, the enterprise would maintain developing, by mechanical automation.

\section{MECHANICAL AUTOMATION DESIGN}

The design of mechanical automation in food factory is divided to 2 aspects [6]. First is the design of food factory, including layout, producing shop, power shop, transport, automation instrumentation, heating, ventilation, environmental protection, office. Second is mechanical automation design, which automatically controls machines without human work by computer technology. So, mechanical automation in food factory is the process of intelligent management by computer in food production [7].

Mechanical automation in advanced countries develops to set of equipment instead of single machine [8]. In set of equipment, the stability and speed of produce improves, and the automation control is better. It is more flexible in produce, structure, providing with the set of equipment. After computer technology getting in especially, there is less error in produce proceed and pollution to the environment [9].

The most important in set of equipment is the mechanical automation control.

Stretch film packing machine is a common mechanical automation module [10]. The process of mechanical automation control is introduced by the design of stretch film packing machine. Stretch film packing machine is used to pack the massive food into packing bag, then pump the air in the bag for the vacuum degree, with the purpose of deoxidizing. This technology is widely used in massive food packing area. 


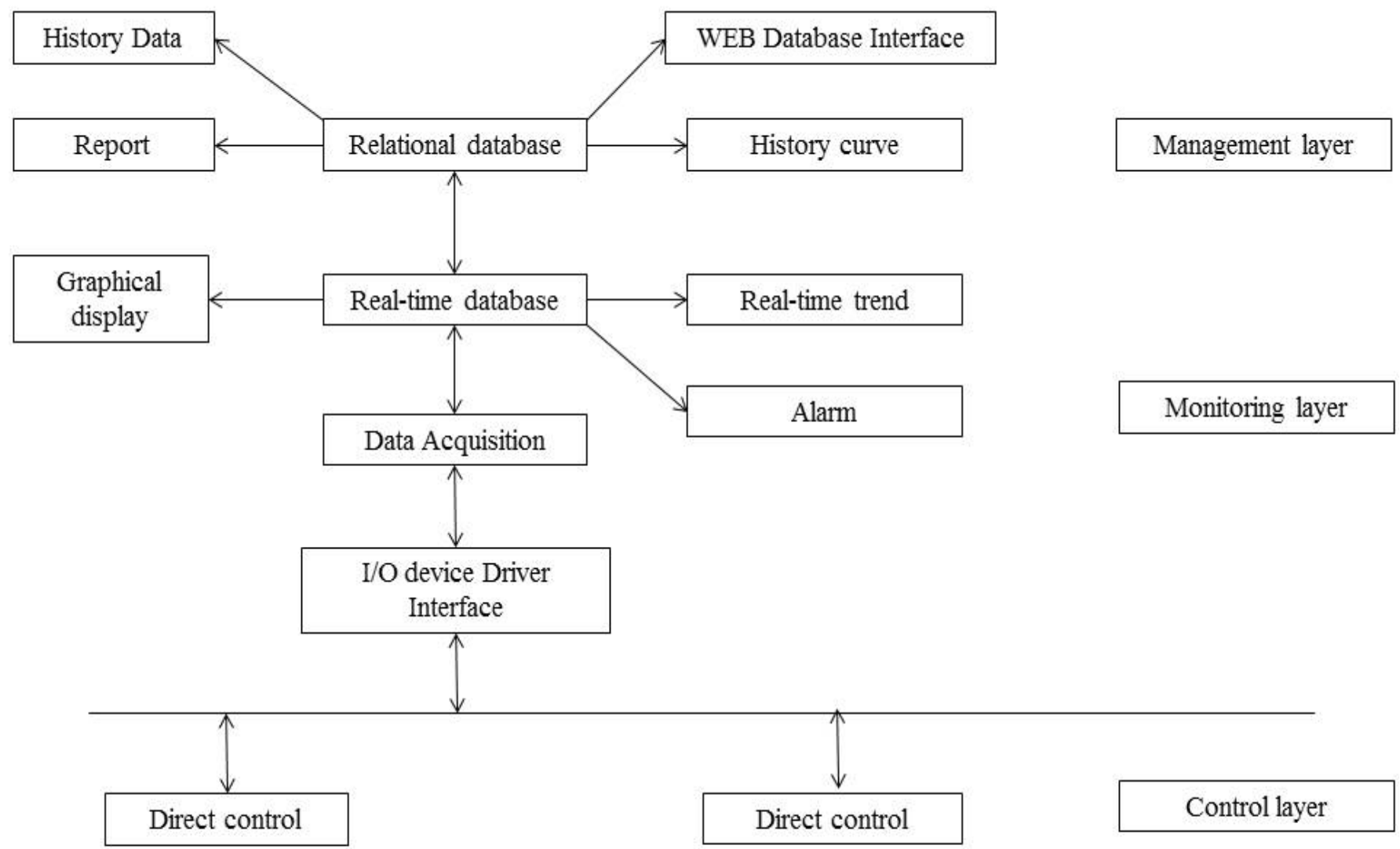

Fig. (1). Software structure of monitoring system of production line.

Base on the production line for massive food packing, Determine the overall structure of the control system after analysis the technical requirements of the production line for massive food packing, and divide the controlling system into vision and monitoring section. Then the visual and monitoring system on it are developed to achieve fullautomatic producing

\subsection{Monitoring System Design}

Consider the functional requirement of the monitoring system, set up the hardware configuration with the pattern of "touch screen \& PLC". Design the graphic interface configuration in the produce module as the core. Design the real-time database of the monitored points base on their characteristics. Develop the controlling circuit configuration follow the controlling requirements of the monitoring system of the production line. Design the statements configurations for the convenience of users. Design the monitoring system graphic interface of the production line using the touch screen as the hardware.

As shown in Fig. (1), there are 4 four parts of configuration software structure: graphical interface system, real-time database, I/O device drive, communication program. These function can be used in monitoring system

1. View the live scene of workshop;

2. Print data reports and view historical curve;

3. Find alarm and check malfunction timely;

4. Modify the technical parameters of packaging production line.

\subsection{The Pick-and-Place Manipulator Control}

According to the controlling characteristics of the pickand-place manipulator, build the hardware structure using "IPC + PMAC card + servo drive and servo motor" model. Develop the controlling system which is based on the PWEIN software platform of the PMAC, so as to achieve the objective of kinematics inverse solution and pick-and-place positioning of the manipulator.

The pick-and-place manipulator is used to pick and place food to the specific position in order to control food automatically. So it is necessary to control the pick-andplace manipulator by entered parameters. Analyze the kinematics of the pick-and-place manipulator.

The structure of the pick-and-place manipulator is showed in Fig. (2a), and it is simplified to Fig. (2b) in kinematics analysis.
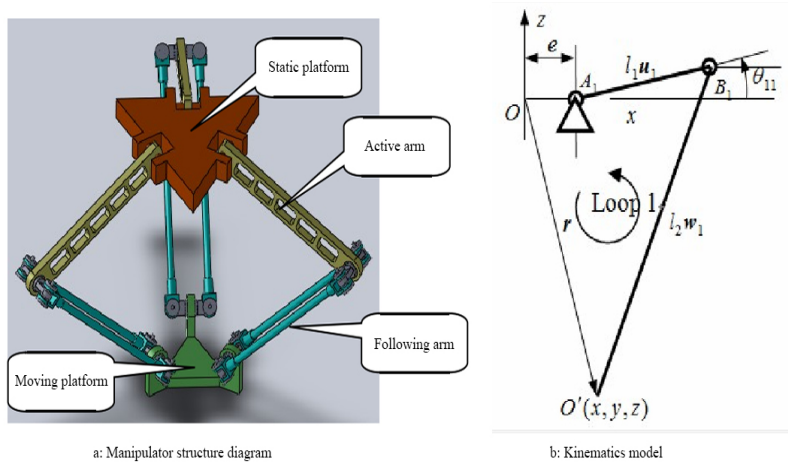

Fig. (2). Manipulator stucture diagram and kinematics modlel. 
Establish coordinates in static platform, the position of moving platform is

$\overrightarrow{\mathrm{r}}-\overrightarrow{\mathrm{e}}_{1}-l_{1} \vec{u}_{i}=l_{2} \vec{w}_{i}, i=1,2,3$

$l_{1}, l_{2}$ is the length of active arm and following arm in chain i. is the radius difference of moving platform and static platform.

$A_{\mathrm{i}} \sin \theta_{i}+B_{i} \cos \theta_{i}+C_{i}=0, i=1,2,3$

Here,

$A_{\mathrm{i}}=-2 \mathrm{l}_{1} z$,

$B_{i}=-2 l_{1}\left(x \cos \phi_{i}+y \sin \phi_{i}-e\right)$

$C_{i}=x^{2}+y^{2}+z^{2}+e^{2}+l_{1}^{2}-l_{2}^{2}$

$-2 e\left(x \cos \phi_{i}+y \sin \phi_{i}\right)$

Then $\vec{u}_{i}, \vec{w}_{i}$ determine.

Based on the coordinate value of trajectory, get the motor rotation angel after mathematical operation. According to the controlling characteristics of the pick-and-place manipulator, build the hardware structure using "IPC + PMAC card + servo drive and servo motor" model. Develop the controlling system which is based on the PWEIN software platform of the PMAC, so as to achieve the objective of kinematics inverse solution and pick-and-place positioning of the manipulator.

\subsection{Manipulator Pick-Up Location Experiment}

The test is to measure the positioning accuracy of the manipultor picking-and-placing in work space. Theoretical value is given to control the movement. 15 coordinate points are teste. The result is shown in Table $\mathbf{1}$.

From the Table 1, the movement direction of manipulator is the same as setted parameters. In direction, there is no difference. Concerning the accuracy, the average deviation in $\mathrm{X}$ is $5.89 \%$, and in $\mathrm{Y}$ is $6.71 \%$ some compensation means should be carrried out.

\subsection{Images Capture and Control}

To control the movement of food accurately, capture images of objects direct by camera. Then optimize the image in computer, to get accurate information which influence the location of the food. So, our eyes are replaced by the visual system.

Image Acquisition and proceeding is carried on virtual instrument development PC software platform, which uses "IPC +CF-F2031T2-A+B BASLER A602fc" as hardware platform, and LabVIEW, IMAQ Vision as software platform. Some effort is made to achieve the purpose of image collecting, distortion correcting, median filtering and canny edge detecting, so as to reach the extraction and

Table 1. Manipulator pick-up location experimental results.

\begin{tabular}{|c|c|c|c|c|c|c|c|c|}
\hline & \multicolumn{2}{|c|}{ Theoretical Value } & \multicolumn{2}{|c|}{ Actual Value } & \multicolumn{2}{|c|}{ Absolute Difference } & \multicolumn{2}{|c|}{ Difference/Theoretical Value } \\
\hline & $\mathbf{X}$ & $\mathbf{Y}$ & $\mathbf{X}$ & $\mathbf{Y}$ & $\mathbf{X}$ & $\mathbf{Y}$ & $\mathbf{X} / \mathbf{X}$ & $\mathbf{Y} / \mathbf{Y}$ \\
\hline 1 & 0 & 50 & 0 & 53.8 & 0 & 3.8 & 0 & 0.076 \\
\hline 2 & 0 & -50 & 0 & -54 & 0 & 4 & 0 & 0.08 \\
\hline 3 & 50 & 0 & 52.1 & 0 & 2.1 & 0 & 0.042 & 0 \\
\hline 4 & -50 & 0 & -52.4 & 0 & 2.4 & 0 & 0.048 & 0 \\
\hline 5 & -50 & -50 & -52.4 & -53.5 & 2.4 & 3.5 & 0.048 & 0.07 \\
\hline 6 & -50 & 50 & -52.9 & 53.8 & 2.9 & 3.8 & 0.058 & 0.076 \\
\hline 7 & 50 & 50 & 53 & 53.8 & 3 & 3.8 & 0.06 & 0.076 \\
\hline 8 & 50 & -50 & 52.4 & -53.5 & 2.4 & 3.5 & 0.048 & 0.07 \\
\hline 9 & 40 & 20 & 38.5 & 21.6 & 1.5 & 1.6 & 0.0375 & 0.08 \\
\hline 10 & 30 & -20 & 32.1 & -21.4 & 2.1 & 1.4 & 0.07 & 0.07 \\
\hline 11 & 7 & 7 & 5.8 & 6 & 1.2 & 1 & 0.171429 & 0.142857 \\
\hline 12 & -7 & 42 & -7.5 & 44.1 & 0.5 & 2.1 & 0.071429 & 0.05 \\
\hline 13 & -35 & -16 & -37.5 & -17.2 & 2.5 & 1.2 & 0.071429 & 0.075 \\
\hline 14 & -35 & -37 & -37.6 & -39.7 & 2.6 & 2.7 & 0.074286 & 0.072973 \\
\hline 15 & 33 & -16 & 35.8 & -17.1 & 2.8 & 1.1 & 0.084848 & 0.06875 \\
\hline Standard deviation & & & & & & & 0.021564 & 0.024568 \\
\hline Average deviation & & & & & & & 0.058995 & 0.067172 \\
\hline
\end{tabular}




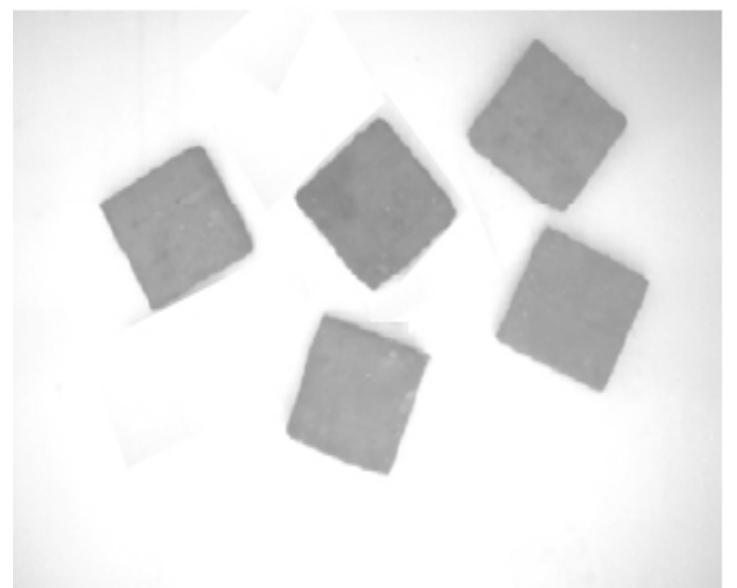

a: Effect diagram of median filtering

Fig. (3). The effect of median filtering and canny edge detecting.

identification of the image feature information of the massive food. The methods of median filtering and canny edge detecting are shown as follows:

Median filtering is arrange the neighborhood according to the size of gray value, then use the intermediate values as the general gray value. Median filtering is defined as:

$Y_{i, j}=\underset{W}{\operatorname{Median}}\left[X_{i+m, j+n}(m, n) \in W\right]$

In median filtering, $W$ is $2 \mathrm{D}$ window which is $5 * 5$ generally. $X_{i, j}$ is a point in the image, $Y_{i, j}$ is the output. Edge enhancement information can make the edge and outline clear. It is the average differential treatment:

$G[\mathrm{f}(x, y)]=\left[\left[\frac{\partial f}{\partial x}\right]^{2}+\left[\frac{\partial f}{\partial y}\right]^{2}\right]^{1 / 2}$

For digital image processing,

$G[\mathrm{f}(x, y)]=\left\{\begin{array}{l}{[f(i, j)-f(i+1, j)]^{2}} \\ +[f(i . j) f(i, j+1)]^{2}\end{array}\right\}^{2}$

In canny edge detection method, Two - dimensional Gaussian function is used to smooth the image, which is defined as:

$G(\mathrm{x}, y)=\frac{1}{2 \pi \delta^{2}} e^{-\frac{x^{2}+y^{2}}{2 \delta^{2}}}$

$\nabla G(\mathrm{x}, y)=\left[\begin{array}{l}\partial G(\mathrm{x}, \mathrm{y}) / \partial \mathrm{x} \\ \partial G(\mathrm{x}, \mathrm{y}) / \partial \mathrm{y}\end{array}\right]$ filter:

Decomposed the template into two one-dimensional

$\frac{\partial G(x, y)}{\partial x}=k x e^{-\frac{x^{2}}{2 \delta^{2}}} e^{-\frac{y^{2}}{2 \delta^{2}}}=h_{1}(x) h_{2}(y)$

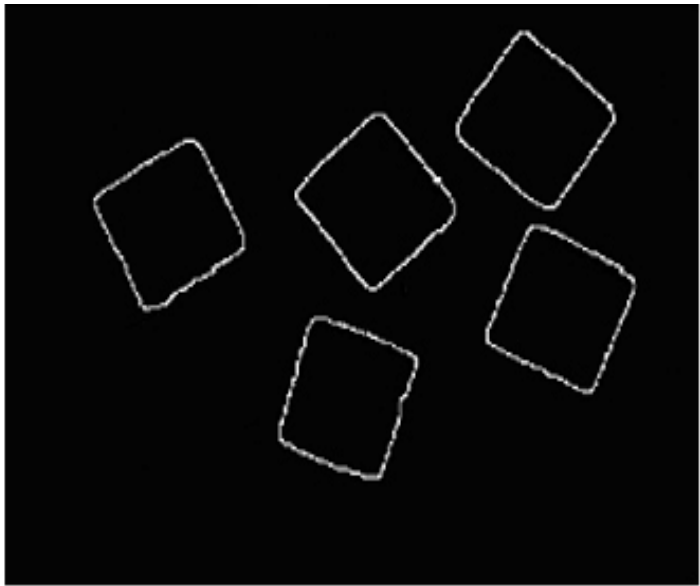

$\mathrm{b}$ : Effect diagram of canny edge detecting

$\frac{\partial G(x, y)}{\partial x}=k x e^{-\frac{y^{2}}{2 \delta^{2}}} e^{-\frac{x^{2}}{2 \delta^{2}}}=h_{1}(\mathrm{y}) h_{2}(\mathrm{x})$

Caculate the volume integral of the two template and image $\mathrm{f}(\mathrm{x}, y)$ :

$\left\{\begin{array}{l}E_{\mathrm{x}}=\frac{\partial G(x, y)}{\partial x} * f(x, y) \\ E_{\mathrm{y}}=\frac{\partial G(x, y)}{\partial y} * f(x, y)\end{array}\right.$

If $W(i, j)=\sqrt{E_{\mathrm{x}}^{2}+E_{\mathrm{y}}^{2}}, \varphi(i, j)=\arctan \frac{E_{y}}{E_{x}}$, the $W(i, j)$ and $\varphi(i, j)$ is the magnitude and direction of the gradient.

Through these methods, the effect of median filtering and canny edge detecting is checked. Good filtering and edge detecting ability is shown in Fig. (3).

Analysis the effect of the visual system of the pick-andplace manipulator, design the hardware system structure with the "CMOS camera+1394 image capture card" model. Develop image detecting software system which is based on LabView and IMAQ Vision platform. This system can achieve the purpose of image collecting, distortion coorecting, median filtering and canny edge detecting, so as to reach the extraction and identification of the image feature information of the massive food, and on the basis of complete block food in movement in the process of tracking process and positioning design.

\section{CONCLUSION}

Automation control based software management is the bottleneck of the food factory automation. Through designing the automation monitoring system of food packaging production line, general process of automation control softare design is introduced. And the results shows it is potential that current machains can upgrade to the set of 
eqiupment after further software development. And then it can work automaticly and efficiently, produce goods with low lost and high quality.

\section{CONFLICT OF INTEREST}

The author confirms that this article content has no conflict of interest.

\section{ACKNOWLEDGEMENTS}

Declared none.

\section{REFERENCES}

[1] R. Bendraou, J.M. Jézéquel, M.P. Gervais, and X.A. Blanc, "A comparison of six uml-based languages for software process modelling", IEEE Transactions on Software Engineering, vol. 36, no. 5, pp. 662-675, 2012.

[2] D. Beymer, P. McLauchlan, B. Coifman and J. Malik, "A real-time computer vision system for measuring traffic parameters", In: Proceedings of IEEE Computer Society Conference on Computer Vision and Pattern Recognition, 1997, pp. 495-501.

[3] Y. W. Deng, Development of a Sectorial Laser Beam Scanning Measuring System Assisted with an Image Processing System,
Master Thesis, National Taiwan University of Science and Technology, 2008.

[4] S. Jang, "Automation manufacturing systems technology for optoelectronic device packaging",. In: Proceedings of the $50^{\text {th }}$ Electronic Components and Technology, 2000, 2000, pp. 10-14.

[5] Y. Kurita, Y. Matsumura, Y. Inoue, F. Tomita, S. Takemura and K. Yokoi, "Real-time motion analysis using CCD camera", Journal of Environment and Engineering, vol. 5, no. 1, pp. 144-156, 2010.

[6] H. Lin, and H.J. Lin, "Remote video monitoring and controling system based on web services", Advanced Materials Research, vol. 383, pp. 4439-4445, 2012.

[7] T. Qiu, "Evaluating model of mechanical automation with fuzzy number intuitionistic fuzzy information", IJACT: International Journal of Advancements in Computing Technology, vol. 3, no. 6, pp. 42-47, 2011.

[8] D. M. Tsai, and T.Y. Huang, "Automated surface inspection for statistical textures", Image and Vision Computing, vol. 21, no. 4, pp. 307-323, 2006

[9] A. Vivas, and P. Poignet, "Predictive functional control of a parallel robot", Control Engineering Practice, vol. 13, no. 7, pp. 863-874, 2012.

[10] C. Wang, F. Zhou, and J.S.M. Vergeest, "On the optimization of multi-objectives with unquantifiable factors". In: The First World Congress on Global Optimization in Engineering \& Science (WCGO'2009), Zhangjiajie, Hunan, China, vol. 5, pp. 1-5, 2009.

(C) Xu Xi; Licensee Bentham Open.

This is an open access article licensed under the terms of the (https://creativecommons.org/licenses/by/4.0/legalcode), which permits unrestricted, non-commercial use, distribution and reproduction in any medium, provided the work is properly cited. 